\title{
Metamorphic Changes in the Blood Sugar and the Pancreatic Islets of the Frog, Rana clamitans ${ }^{1,2}$
}

\author{
B. E. FRYE \\ Department of Zoology, University of Michigan, Ann Arbor, Michigan
}

The pancreatic islets of several species of amphibians undergo differentiation from a larval to an adult type at the time of metamorphosis (Frye, '59). Some of the changes include an increase in the amount of cytoplasm, an increase in cytoplasmic basophilia and affinity for standard pancreatic stains, lengthening of the cells and pronounced polarization toward the capillaries, and an accumulation of histochemically demonstrable insulin. This description pertains to the insulin-secreting beta cell, which is the only, or strongly predominant cell type in the amphibian islet (Miller, '60). The total picture is suggestive of a functional differentiation of the beta cell during the period of metamorphosis. If this interpretation is correct the greater part of larval life must be spent without insulin, which is an indispensable factor in the blood sugar homeostasis of adult vertebrates.

Two other lines of evidence are in accord with the histological and histochemical data: (a) extirpation of the dorsal pancreatic rudiment of embryos of the salamander, Ambystoma punctatum - an operation which results in total absence of islets of Langerhans in the larva - has no effect upon larval survival or the rate of growth and differentiation (Frye, '62); (b) in Rana pipiens larvae subjected to subtotal pancreatectomy no significant elevation of blood glucose values was observed, nor was growth inhibited so long as digestion was not impaired (Frye, unpublished data).

The purpose of this report is to describe some experiments which test the hypothesis that the larval pancreatic islets are non-functional or weakly functional and only attain full functional status after metamorphosis.

\section{MATERIALS AND METHODS}

Blood glucose levels and glucose tolerance have been determined for both nor$\mathrm{mal}$ and depancreatized specimens of the green frog, Rana clamitans, at several stages of metamorphosis (table 1). The frogs and tadpoles used in this study were collected from a wild population in a pond near the Mountain Lake Biological Station in southwestern Virginia. They were kept at room temperature and used within 24-72 hours after collection.

Pancreatectomy was performed under MS 222 anesthesia. ${ }^{3}$ For tadpoles of stage XIX or younger, a short longitudinal incision was made in the right side of the abdomen over the duodenal loop. The loop and attached pancreas were pulled out through the incision. Blood vessels entering and leaving the gland were compressed for a few seconds with jeweler's forceps, to cause hemostasis and prevent subsequent bleeding, after which the gland was removed with two pairs of jeweler's forceps. The incision was closed with a strand of silk unraveled from surgical thread, glued to a small headless insect pin for suturing. In the adult a similar method was used except the pancreas was approached through an incision on the left side over the posterior end of the stomach. At stage XXII the position of the pancreas varies, but it could usually be located through a medial ventral incision parallel to the ventral abdominal vein just behind the liver.

\footnotetext{
1 Supported by Public Health Service Grant no. AM05818-03, and by a grant from the Rackham School of Graduate Studies, University of Michigan. Most of the experimental work was carried out at the This paper is dedicated to the memory of Dr. Elizabeth L. Sawyer, who was my most highly Elizabeth L. Sawyer, who was my most highly esteemed friend and teacher. She set an unexcelled
example of dedication to high standards of teaching. 3 Tricaine methanesulfonate, Sandoz Pharmaceuticals.
} 
Blood sugar values were determined with the anthrone reagent (Morris, '48) on $0.02-0.08 \mathrm{ml}$ of blood taken from the heart and deproteinized according to the method of Folin and Wu ('19). To test the glucose tolerance, glucose was injected intraperitoneally at a dose of $2.5 \mathrm{gm} / \mathrm{kg}$ as a $10 \%$ solution, and blood samples were taken three hours later. Trial experiments using different glucose doses, shorter postinjection intervals, and intracardiac route of injection indicated the above procedure to be the best choice.

The pancreases were removed after bleeding, fixed in Bouin's fluid, embedded in paraffin and sectioned at $8 \mu$. Sections were stained histologically with aldehyde fuchsin (Gomori, '50) or Gomori's azan (Gomori, '39). Histochemical methods for insulin were those of Barrnett et al. ('55) and of Schiebler and Schiessler ('59).

\section{RESULTS}

\section{Blood sugar}

The changes in blood sugar and glucose tolerance during metamorphosis, and the effects of pancreatectomy, are summarized in table 1 and in figures 1 and 2 . The normal larval blood sugar level averages about $25 \mathrm{mg}$ per cent (stages V, XI). During the metamorphic climax (stages XIX, XXII) there is a significant rise $(P=0.002)$ from these larval values to an adult level averaging $40-45 \mathrm{mg}$ per cent. The effect of pancreatectomy on blood sugar level depends upon the stage of metamorphosis being studied. Forty-eight hour post-operative sugar values are not significantly altered ( $P=0.1$ ) by pancreatectomy during early metamorphosis (stage $V$ ) or during the metamorphic climax (stage XXII). However, during metamorphosis (stage XI and XIX) and in the young and adult frog rather pronounced diabetic glucose levels $(P=0.001)$ occur following the same operation (fig. 1).

The larvae have greatest tolerance to a glucose load, the three hour post-injection values being elevated about $20 \mathrm{mg}$ per cent at stage $\mathrm{V}$, whereas during later metamorphosis and in the frog tolerance is substantially lower, the blood sugar increase being in the order of 50-60 mg per cent. Pancreatectomy significantly decreases glucose tolerance at all stages, but the largest effect is at stages XI, XIX, XXV and in the adult (average increase over normal glucose tolerance is $50-60 \mathrm{mg}$ per cent), whereas in the stage $\mathrm{V}$ larva and at the metamorphic climax (XXII) the effect is much less, the increase being 20-30 mg per cent (fig. 2).

TABLE 1

Blood glucose and glucose tolerance of normal and depancreatized animals

\begin{tabular}{|c|c|c|c|c|c|c|}
\hline \multirow{2}{*}{ Group } & \multicolumn{6}{|c|}{ Stage 1} \\
\hline & $\mathbf{V}$ & $\mathbf{X I}$ & XIX & XXII & $\mathrm{XXV}$ & Adult \\
\hline \multicolumn{7}{|l|}{ Normal } \\
\hline $\begin{array}{l}\text { Number } \\
\text { Blood sugar } 2 \\
\text { (Range) }\end{array}$ & $\begin{array}{c}8 \\
24 \pm 1.9 \\
(17-35)\end{array}$ & $\begin{array}{l}8 \\
22 \pm 1.9 \\
(17-33)\end{array}$ & $\begin{array}{l}10 \\
37 \pm 2.7 \\
(28-57)\end{array}$ & $\begin{array}{c}16 \\
39 \pm 2.0 \\
(24-55)\end{array}$ & $\begin{array}{c}8 \\
44 \pm 3.7 \\
(35-51)\end{array}$ & $\begin{array}{c}10 \\
40 \pm 2.7 \\
(28-58)\end{array}$ \\
\hline \multicolumn{7}{|l|}{ Depancreatized } \\
\hline $\begin{array}{l}\text { Number } \\
\text { Blood sugar } \\
\text { (Range) }\end{array}$ & $\begin{array}{c}7 \\
32 \pm 2.9 \\
(22-43)\end{array}$ & $\begin{array}{c}7 \\
85 \pm 10.9 \\
(54-126)\end{array}$ & $\begin{array}{c}10 \\
79 \pm 10.9 \\
(40-134)\end{array}$ & $\begin{array}{c}8 \\
50 \pm 4.8 \\
(32-52)\end{array}$ & $\begin{array}{c}9 \\
115 \pm 7.9 \\
(67-153)\end{array}$ & $\begin{array}{c}8 \\
75 \pm 4.9 \\
(59-97)\end{array}$ \\
\hline \multicolumn{7}{|c|}{ Normal, glucose tolerance } \\
\hline $\begin{array}{l}\text { Number } \\
\text { Blood sugar } \\
\text { (Range) }\end{array}$ & $\begin{array}{c}10 \\
46 \pm 5.3 \\
(36-71)\end{array}$ & $\begin{array}{l}9 \\
65 \pm 4.8 \\
(48-94)\end{array}$ & $\begin{array}{c}8 \\
76 \pm 3.8 \\
(63-96)\end{array}$ & $\begin{array}{c}9 \\
97 \pm 5.1 \\
(83-126)\end{array}$ & $\begin{array}{c}8 \\
105 \pm 6.1 \\
(81-126)\end{array}$ & $\begin{array}{c}8 \\
88 \pm 3.4 \\
(75-106)\end{array}$ \\
\hline \multicolumn{7}{|c|}{ Depancreatized, glucose tolerance } \\
\hline $\begin{array}{l}\text { Number } \\
\text { Blood sugar } \\
\text { (Range) }\end{array}$ & $\begin{array}{c}6 \\
75 \pm 5.4 \\
(63-87)\end{array}$ & $\begin{array}{c}9 \\
117 \pm 10.8 \\
(90-197)\end{array}$ & $\begin{array}{c}10 \\
140 \pm 9.5 \\
(102-157)\end{array}$ & $\begin{array}{c}7 \\
118 \pm 5.8 \\
(94-138)\end{array}$ & $\begin{array}{c}7 \\
164 \pm 6.5 \\
(110-208)\end{array}$ & $\begin{array}{c}8 \\
138 \pm 3.9 \\
(126-157)\end{array}$ \\
\hline
\end{tabular}

I Staged according to the normal metamorphosis series of Taylor and Kollros ('46) for Rana pipiens. Adults were breeding males weighing 20-40 grams.

2 Blood sugar expressed as mg per cent \pm standard error of the mean. 


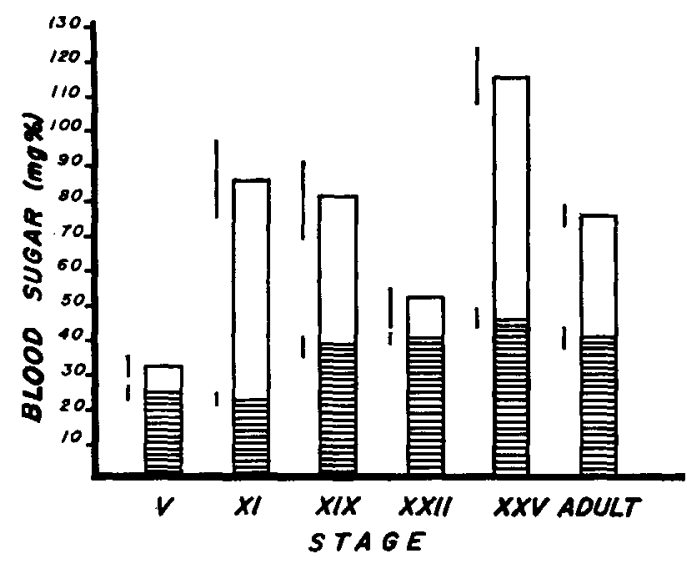

Fig. 1 Normal blood glucose levels at various stages of metamorphosis (barred) and the effects of pancreatectomy (open). The lines to the left of each bar show standard errors.

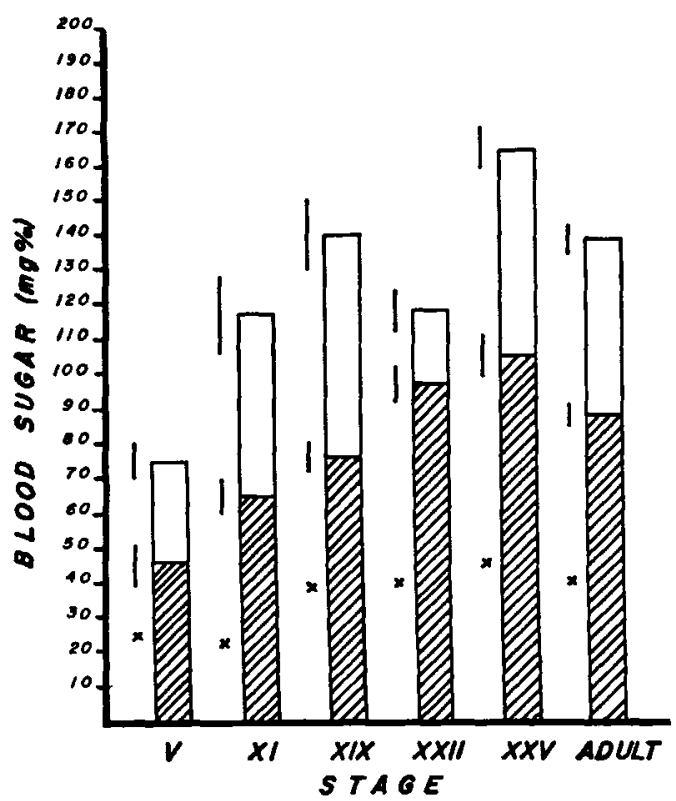

Fig. 2 The effect of pancreatectomy upon glucose tolerance. Cross-hatched: glucose tolerance of intact animals; open: glucose tolerance after pancreatectomy. The lines to the left of each bar show standard errors. The $x$ 's indicate normal blood glucose values at the corresponding stages.

\section{Histology and histochemistry}

The major histological features of the amphibian pancreatic islets have been previously described on several occasions (cf. Miller, '60; Kern, '62; Frye, '58). Therefore I shall summarize here only the major features which undergo change during metamorphosis. In Rana clamitans the islets are composed exclusively of beta cells. I have thus far failed to demonstrate typical beta granulation in the cells of this species, by means of the histological dyes used, even though rat pancreas fixed and stained the same way shows clear granulation of the beta cells, especially with aldehyde fuchsin. Interestingly, however, the pseudoisocyanine staining is distinctly granular after the same (Bouin) fixation (fig. 11).

In the adult the beta cells are columnar (fig. 3) and arranged in irregular palisades or "cords." There is no distinct connective tissue capsule, and the islets are asymmetrically shaped, without distinct demarcation from the acinar tissue. The cords of cells intertwin among large capillary sinusoids; typically two surfaces of these cells are exposed to sinuses. Thus a cord as a whole appears to be bipolar (with two secreting surfaces), but the individual beta cells probably secrete toward only one surface (figs. 10, 11). The nucleus is basal and there is an apical cap of cytoplasm which stains with increasing basophilia toward the capillary pole.

The larval islets (stage III and older) are much smaller on the average than those of the adult, and the beta cells are grouped into tight "glomerular" knots which protrude into large capillary sinusoids (figs. 4, 5, 7). The cells are low cuboidal and without distinct histological polarization (fig. 4). Central cells in such islets appear to have no surface in direct contact with a capillary. During metamorphosis this larval condition prevails in general through stage XIX, although some maturation, i.e., increase in islet size, beta cell height, and the palisaded conformation does occur during the larval period. A rapid, but not abrupt, transition toward the adult conformation occurs between XIX and XXV. In the young froglet (XXV) the islets are columnar and polar, but not so tall as in the mature feeding adult. Maximum cell height probably is not attained until after feeding is resumed.

Histochemical observations on the distribution of isulin are based mainly on the metachromatic pseudoisocyanine method of Schiebler and Schiessler ('59) 
which gives a clearer and apparently more specific localization of insulin than the sulfhydryl method of Barrnett et al. ('55). In the froglet or the adult frog the distribution of insulin is highly polar, and since virtually every cell stains, it appears as a band along the capillary borders of the islet. The band is relatively narrow and varies in intensity in the froglet (fig. 10 ), but is usually very broad and intense in the adult (fig. 11). In tadpoles insulin is present at all stages examined. During the earlier premetamorphic stages (IIIVIII) the reaction is usually weak to moderate (figs. 5, 6) and becomes more intense in older larvae (figs. 7,8 ). In the larval beta cell the insulin is localized as a supranuclear cap, presumably in the Golgi zone of the cell. Since not all cells are positive in any particular islet the effect is spotty, rather than banded as in the adult. Between stage XIX and XXII there is a marked accumulation of insulin in the islets (fig. 9), which in many cases considerably exceeds that seen in the adult. This accumulation is reduced during the final stages of metamorphosis to give the moderate polar band seen in the young frog.

\section{DISCUSSION}

Normal pancreatic regulation of blood glucose is initiated during metamorphosis, between stage V and XI in the case of Rana clamitans. This conclusion is based upon the effects of pancreatetcomy which are first apparent at stage XI. Unpublished experiments on the grass frog ( $R$. pipiens) and on the neotenic form of the tiger salamander (Ambystoma tigrinum, from near Boulder, Colorado) have also failed to demonstrate an appreciable hyperglycemic response to total pancreatectomy in the larval stages, although hyperglycemia does occur after pancreatectomy of the metamorphosed adults. The high glucose tolerance as well as the low normal blood sugar values of the premetamorphic larva are, therefore, related to extrapancreatic factors.

The fact that pancreatectomy significantly impairs glucose tolerance in the younger stages suggests that the pancreatic islets do have secretory ability when "challenged" by exogenous glucose.
However, the fraction of tolerance attributable to the pancreas is only about $30 \mathrm{mg}$ per cent at stage $V$, as opposed to 50-60 $\mathrm{mg}$ per cent in the later stages.. This bears out the suggestion that other factors are important in glucose regulation by the larva. Thus the differences in blood glucose levels, glucose tolerance, and response to pancreatectomy between larva and adult are due to some larval mechanism which promotes removal of glucose from the blood, independently of insulin, and which is altered or effectively counteracted by changes which take place during metamorphosis. Possible mechanisms include the following:

1. High insulin-independent glucose permeability of tadpole tissues. This would obviate insulin control of glucose entry into the intracellular fluid space (cf. Young, '63) and would account for the lack of a diabetic response to pancreatectomy as well as the higher glucose tolerance of the tadpole as compared to the frog. I have done preliminary experiments (unpublished) with tadpoles of $R$. pipiens demonstrating that insulin-induced hypoglycemia is possible in tadpoles and therefore that if the tadpole tissues have a higher "spontaneous" permeability to glucose it is only partially independent of insulin, i.e., it can be augmented by exogenous hormone. Nonetheless, the possibility of a relatively greater insulinindependent glucose space in the tadpole is a strong one. This is especially so in view of the demonstrated appearance of an "insulin-sensitive membrane" during the development of the chick embryo heart (Guidotti, Kanameishi and Foa, '61; Guidotti and Foa, '61). According to these important investigations uptake of glucose by embryonic chick heart muscle is limited by the rate of glucose phosphorylation from the fifth to the seventh day of incubation, but is subsequently limited by the rate of membrane transport, concomitant with the development of insulin-sensitive transport.

2. Altered liver carbohydrate metabolism. It is established that many aspects of metabolism are altered during metamorphosis (cf. Frieden, '61), and certain investigations support the probability that liver metabolism is altered in a way which 
would elevate blood glucose levels. Liver glycogen is mobilized during metamorphosis (Faraggiana, '33; Urbani, '57) and hepatic glucose-6-phosphatase, an enzyme important in glycogen mobilization, also increases during metamorphosis, or may be augmented precociously by thyroxine treatment (Frieden and Mathews, '58). Changes in liver intermediary metabolism could presumably elevate blood glucose levels by elevating the glucose "threshold" at which net glycogen deposition or mobilization would occur. In connection with this hypothesis it is significant that the adrenal cortex, which has powerful effects upon liver function, matures functionally during metamorphosis (Rapola, '63). Glucocorticoids enhance gluconeogenesis, inhibit glycogenesis, inhibit glucose phosphorylation, and increase the activity of glucose-6-phosphatase; all these effects contribute to the hyperglycemic action of cortical hormones.

3. Glucose excretion. Possibly the larva loses glucose readily through the kidneys, gills or skin. Although this is not likely to be a physiological mechanism for the regulation of normal blood glucose levels, it could contribute significantly to the glucose tolerance of the animal. We have shown that large doses of glucose are excreted rapidly by tadpoles through the kidneys, not through the skin or gills, since ligation of the cloacal tail piece blocks excretion of the glucose into the medium (unpublished observations). Whether this phenomenon is significant in the present context will depend on demonstration of significantly higher renal glucose thresholds in the frog than in the tadpole.

Maturational changes in the histology of the islets of Langerhans have been previously interpreted as primary or causal to alterations in carbohydrate metabolism (Aron, '28a, '28b; Frieden, '61; see Frye, '59). According to this view insulin secretion is initiated under the influence of thyroxine during metamorphosis, and in turn affects carbohydrate metabolism in the liver ${ }^{3}$ and other tissues. A better interpretation, however, is that functional "activation" and histological maturation of the islets and beta cells are secondary to the metabolic changes which elevate blood glucose levels. Two reasons for this opinion are: (1) insulin is a hypoglycemic hormone, and would not occupy a primary position in changes leading to hyperglycemia; (2) chronic hyperglycemia does lead to histological changes indicative of activation, and eventually functional exhaustion of the beta cells (reviewed in Frye, '57). Therefore, the mild elevation in blood sugar during metamorphosis, which we presume occurs for one or more of the reasons discussed above, might be expected to stimulate the biosynthetic and secretory activities of the beta cell. The increasing size and insulin content of the beta cells, as well as the changes in islet size and conformation which we have described, agree well with this interpretation.

\section{SUMMARY AND CONCLUSIONS}

In Rana clamitans there is a significant change in blood sugar levels from larval values of about $25 \mathrm{mg}$ per cent to adult values averaging $40-45 \mathrm{mg}$ per cent. The larva (stage V) does not develop hyperglycemia after pancreatectomy, but has a higher glucose tolerance than the adult. Pancreatectomy does not decrease glucose tolerance as much as in older metamorphosing larvae or frogs. We conclude that the larval pancreatic islets have some secretory capacity, but this capacity does not become important in normal blood glucose regulation until mid-metamorphosis (stage XI). Extrapancreatic factors responsible for low larval glucose values, high glucose tolerance, and the lack of a diabetic response to pancreatectomy have been proposed. The proposals include (1) high insulin-independent permeability of the tadpole tissues, (2) differences in liver metabolism, especially of glycogen, and (3) low renal glucose threshold. Maturational changes in the pancreatic islets are believed to be a consequence, not a cause, of the altered carbohydrate metabolism. The histological evidence is compatible with this interpretation.

\section{LITERATURE CITED}

Aron, M. 1928a Le fonctionnement du pancréas chez les larves d'Amphibiens. Compt. rend. soc. biol., 99: 213-215.

3 This interpretation continues to suffer from the fact that the direct effects of insulin upon hepatic carbohydrate metabolism are not clear or unequivocal (Randle, '63; see Frye, '59). 
1928b Corrélation fonctionelle entre la glande thyroïde et le pancréas endocrine chez les larves d'Amphibiens. Comp. rend. soc. biol., 99: 215-217.

Barrnett, R. J., R. B. Marshall and A. M. Seligman 1955 Histochemical demonstration of insulin in the isles of Langerhans. Endocrinol., 57: $419-438$.

Faraggiana, R. 1933 The presence of glycogen in the liver of fresh tadpole larvae. Atti. accad. Lincei., 18: $580-582$.

Folin, O., and H. Wu 1919 A system of blood analysis. J. Biol. Chem., 38: 81-110.

Frieden, E. 1961 Biochemical adaptation and anuran metamorphosis. Am. Zoologist, 1: 115-149.

Frieden, E., and H. Mathews 1958 Biochemistry of amphibian metamorphosis. III. Liver and tail phosphatases. Arch. Biochem. Biophys., 73: 107-119.

Frye, B. E. 1957 Differentiation of the endocrine pancreas in fetuses of alloxan diabetic and insulin-treated rats. J. Morph., 101: 325358.

1958 Development of the pancreas in Ambystoma opacum. Am. J. Anat., 102: 117140.

1959 The development of function in the islets of Langerhans. In: Symposium on Comparative Endocrinology, ed. A. Gorbman. Wiley, New York, pp. 681-696.

1962 Extirpation and transplantation of the pancreatic rudiments of the salamanders Ambystoma punctatum and Eurycea bislineata. Anat. Rec., 144: 97-107.

Gomori, G. 1939 Studies on the cells of the pancreatic islets. Anat. Rec., 74: 439-460.
1950 Aldehyde fuchsin: a new stain for elastic tissue. Am. J. Clin. Path., 20: 665. Guidotti, G., and P. P. Foa 1961 Development of an insulin-sensitive glucose transport system in chick embryo hearts. Am. J. Physiol., 201: 869-872.

Guidotti, G., D. Kanameishi and P. P. Foa 1961 Chick embryo heart as a tool for studying cell permeability and insulin action. Am. J. Physiol., 201: 863-868.

Kern, H. 1962 Die Cytologie der Langerhansschen Inseln beim Axolotl (Siredon mexicanum) und bei Ambystoma maculatum. Endokrinologie, 42: 294-308.

Miller, M. R. 1960 Pancreatic islet histology and carbohydrate metabolism in amphibians and reptiles. Diabetes, 9: 318-323.

Morris, D. L. 1948 Quantitative determination of carbohydrates with Dreywood's anthrone reagent. Science, 107: 254-255.

Randle, P. J. 1963 Endocrine control of metabolism. Ann. Rev. Physiol., 25: 291-324.

Rapola, J. 1963 The adrenal cortex and metamorphosis of Xenopus laevis Dandin. Gen. and Comp. Endocrinol., 3: 412-421.

Schiebler, T. H., and S. Schiessler 1959 Über der Nachweiss von Insulin mit der Metachromatisch Reagierenden Pseudoisocyaninen. Histochemie, $1: 445-465$.

Urbani, E. 1957 Studi di embriologia e zoologia chemica delgi anfibi. Instituto Lombardo, Rend. Sci., 92: 69-179.

Young, F. G. 1963 Pancreatic hormones: Insulin. In: Comparative Endocrinology, vol. I. ed. U. S. von Euler and H. Heller. Academic Press, New York, pp. 371-409. 


\section{PLATE}


PLATE 1

EXPLANATION OF FIGURES

Abbreviation: c, capillary; several are labeled for perspective and orientation.

Figures 3 and 4 are stained by the method of Barrnett, Marshall and Seligman ('55). $450 \times$.

3 Part of an adult islet illustrating the columnar shape of the beta cells and their orientation toward the capillaries.

4 Stage V larva: for contrast with figure 3, illustrating the smaller size of the beta cells, and typical larval islet conformation.

Figures 5-11 are stained by the pseudoisocyanine method of Schiebler and Schiessler ('59) for insulin. $525 \times$.

5 Stage VIII: there is relatively little insulin, which occurs as a supranuclear cap facing the capillary surface of the cell (arrows). Not all cells stain, hence the spotty effect. This is typical of stage $V$ and VIII larvae.

6 Stage VIII: occasionally, as here, islets of young larvae stain more heavily than usual.

7 Stage XI: staining is still spotty, but is considerably more intense than is usual at younger stages.

8 Stage XIX: insulin occurs more uniformly in most of the beta cells, and perhaps in slightly greater amounts than at stage XI.

9 Stage XXII: relatively intense accumulation of insulin.

10 Stage XXV: part of an islet showing the "bipolar" accumulation of insulin in a relatively narrow band along the capillary surfaces.

11 Adult frog: a small islet, which illustrates typical strong reaction for insulin in a broad pericapillary zone. 


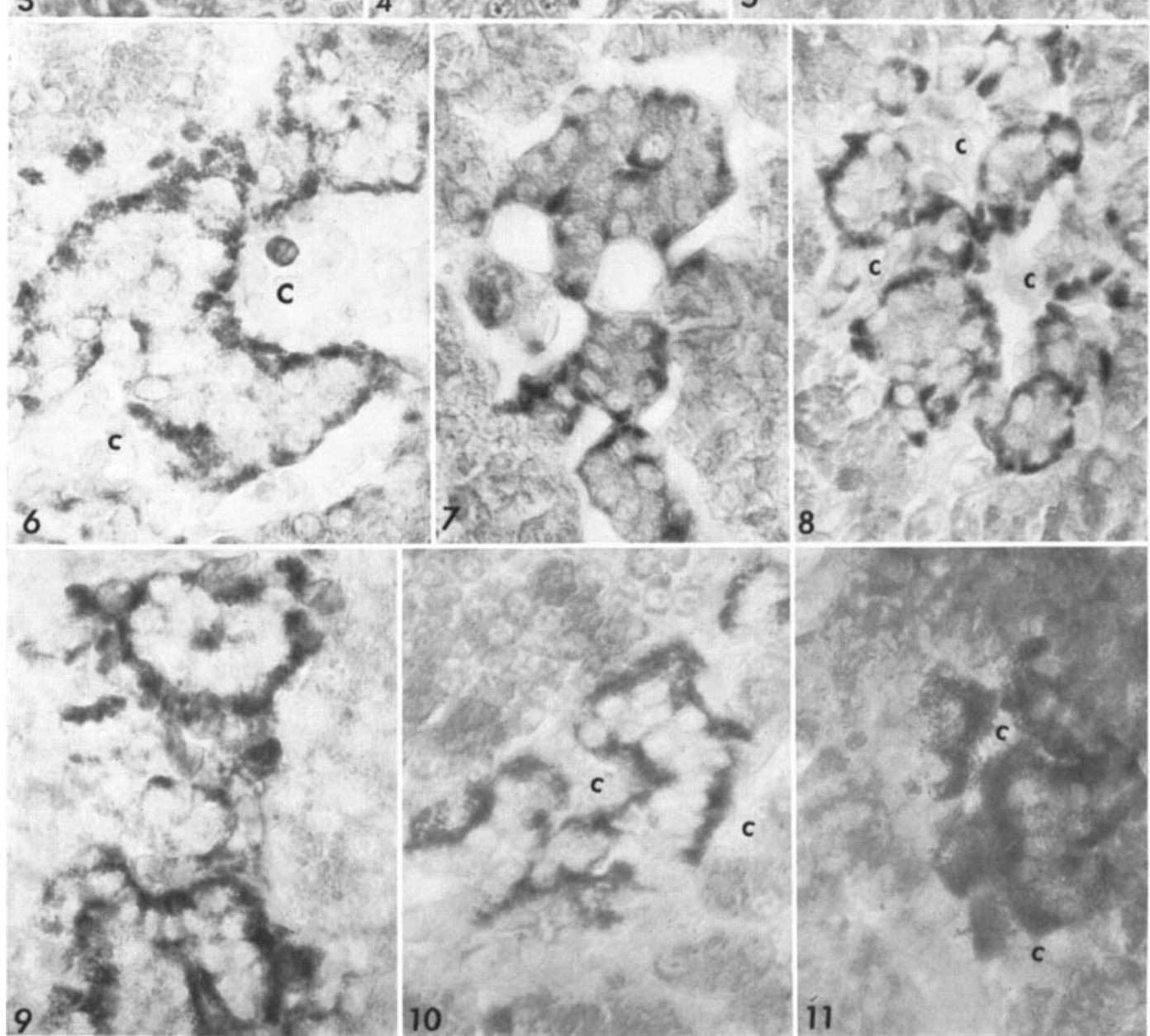

